\title{
Co-morbidities, Maternal and Fetal Outcome of Teenage Pregnancy at Tertiary Care Hospital, Nepal Shrestha $S,{ }^{1} K C D,{ }^{1}$ Dongol $A^{2}$
}

\author{
${ }^{1}$ Department of Nursing \\ ${ }^{2}$ Department of Obstetrics and Gynaecology \\ Dhulikhel Hospital, Kathmandu University Hospital \\ Kathmandu University School of Medical Sciences \\ Dhulikhel, Kavre, Nepal.
}

\section{Corresponding Author}

Subasna Shrestha

Department of Nursing

Dhulikhel Hospital, Kathmandu University Hospital

Kathmandu University School of Medical Sciences

Dhulikhel, Kavre, Nepal.

E-mail: subasnashrestha@gmail.com

\section{Citation}

Shrestha S, KC D, Dongol A. Co-morbidities, Maternal and Fetal Outcome of Teenage Pregnancy at Tertiary Care Hospital, Nepal. Kathmandu Univ Med J. 2020;69(1):59-63.

\section{ABSTRACT}

\section{Background}

Teenage pregnancies constitute a serious health and social problem worldwide. World estimates in 2008 report about 16 million births to adolescent mothers, most of them occurring in low and middle income countries.

\section{Objective}

To assess pregnancy co-morbidities and outcome of teenage pregnancy.

\section{Method}

A cross-sectional study was conducted at obstetrics and gynecological department of Dhulikhel Hospital. Study was conducted for 18 month period from 1-07-2013 to 30-12-2014. All teenage pregnancy cases admitted at the time of study period were enrolled. Purposive sampling technique was used. Data were collected by face to face interview using clinical Performa and through record file of the patient. Collected data were analyzed in SPSS version 21.0.

\section{Result}

Total of 527 teenage mothers of varying age group (15 to 19 years ) were enrolled in the study. Teenagers who had never been to school were $3.0 \% ; 66.2 \%$ of them were from low socioeconomic background, and $58.6 \%$ were from rural areas. Pregnancy co-morbidities detected were, Urinary tract infection (UTI) $18.4 \%$, threatened preterm $12.9 \%$ followed by ante partum hemorrhage $4.7 \%$. However, other major co-morbidities such as hypertensive disorder, gestational diabetes found to be very less such as, hypertension $0.8 \%$ and gestational diabetes found in only one woman.

\section{Conclusion}

Maternal and newborn outcome and co-morbidities among teenage pregnant women found less compare to other studies. Major pregnancy related morbidities such as hypertension, pre-eclampsia and diabetes were found very less. Most common maternal morbidity found was urinary tract infection during pregnancy but statistically not significant. Similarly, newborn mean weight was more than 2.5 $\mathrm{kg}$ and neonatal death found very less. However, teenage pregnancy is significantly associated with low economic status, illiteracy status, willingness to marriage by teenagers and ethnicity.

\section{KEY WORDS}

Awareness, Obstetrical and fetal outcome, Teenage pregnancy 


\section{INTRODUCTION}

Teenage pregnancy is considered as high-risk pregnancy and has enormous negative socioeconomic impact at the individual level as well as on the society. According to World Health Organization (WHO), teenage pregnancy means pregnancy between 10 and 19 years of age. Adolescent pregnancy is a major contributor to maternal and child mortality, and to the vicious cycle of ill-health and poverty. ${ }^{1}$

Worldwide, approximately 16 million girls between the ages of 15 and 19, and two million girls under age 15, become pregnant every year. An estimated three million girls under 20 years sought abortions in 2008, in countries where abortion is illegal and unsafe. ${ }^{2}$

Several factors contribute to adolescent births. In many societies, girls may be under pressure to marry and bear children early, or they may have limited educational and employment prospects. ${ }^{1}$

In low- and middle-income countries, over $30 \%$ of girls marry before they are 18 years of age; around $14 \%$ before the age of 15 . Moreover, married adolescents are likely to become pregnant and give birth in accordance with social norms. ${ }^{1}$

Education, on the other hand, is a major protective factor for early pregnancy: the more years of schooling, the fewer early pregnancies. Birth rates among women with low education are higher than for those with secondary or tertiary education. Some adolescents do not know how to avoid becoming pregnant, or are unable to obtain contraceptives. However, even where contraceptives are widely available, sexually active adolescents are less likely to use contraceptive than adults. ${ }^{1}$

In Nepal, $17 \%$ of women age $15-19$ have begun childbearing; $13 \%$ have had a live birth, and $4 \%$ are pregnant with their first child. ${ }^{3}$ Nepal demographic health survey also mentioned that teenage pregnancy rate hasdeclined from 2001 (21\%) to 2011 (17\%). However, teenage childbearing has remained constant over the past 5 years (17\%) since 2011 to 2016. ${ }^{3}$ Many studies have shown more co-morbidities among teenage pregnancy compare to adult pregnancy in many part of the World. This study is conducted to assess pregnancy comorbidities and outcome of teenage pregnancy.

\section{METHODS}

A cross sectional descriptive study was conducted at obstetric and gynecological department of Dhulikhel Hospital, Kathmandu University Hospital. Study was conducted from 1-07-2013 to 30-12-2014 and teenage mothers were followed up till discharge. All teenage mothers admitted to this department at the time of study period were enrolled. Purposive sampling technique was used. Data was collected through Performa via direct interview with teenagers and pregnancy outcomes were obtained from their case sheet before discharge. Before enrollment, informed consent was taken by researcher.

Study was conducted after getting approval from institutional review committee of Kathmandu University School of medical Sciences. Data was analyzed in SPSS version 21.0. Descriptive data such as mean, median and percentage were analyzed and chi-square test was used to analyze correlation of variables. Level of significance was determined by $p$ value of less than 0.05 .

\section{RESULTS}

There were 527 cases enrolled in this study age varying from 15 years to 19 years of age, mean age was $18.11 \pm$ 0.97849 . Age of less than 17 accounts $23.3 \%$ and more than 17 were $76.7 \%$. Teenagers, who never been to school were $3.0 \%$, followed by primary level of schooling $24.9 \%$, secondary level $34.0 \%$ and grade 12 and above were $26.4 \%$. Economic status of teenage mother shows, low economic status accounts $66.2 \%$ and only $1.3 \%$ were belong to high economic background and $58.6 \%$ of the respondents reside at rural area and $41.4 \%$ are from urban areas. Most of the women, $81.6 \%$ had attended antenatal care clinic (ANC) and $18.4 \%$ never attended ANC clinic. Teenagers who had arranged marriage were $52.6 \%$ and $47.4 \%$ of them had done marriage with their own wish (love marriage).

Table 1. Socio-demographic variables $(\mathrm{N}=527)$

\begin{tabular}{|c|c|c|}
\hline \multicolumn{3}{|l|}{ Demographic characteristics } \\
\hline \multicolumn{3}{|c|}{ Age in years (Mean $=18.11 \pm 0.97849$ ) } \\
\hline$<17$ & 123 & 23.3 \\
\hline$>17$ & 404 & 76.7 \\
\hline \multicolumn{3}{|l|}{ Education } \\
\hline Illiterate & 16 & 3.0 \\
\hline Only can read and write & 62 & 11.8 \\
\hline Primary & 131 & 24.9 \\
\hline Secondary & 179 & 34.0 \\
\hline 12 grade and above & 139 & 26.4 \\
\hline \multicolumn{3}{|l|}{ Economic status } \\
\hline Low & 349 & 66.2 \\
\hline Medium & 171 & 32.4 \\
\hline High & 7 & 1.37 \\
\hline \multicolumn{3}{|l|}{ Address } \\
\hline Urban & 218 & 41.4 \\
\hline Rural & 309 & 58.6 \\
\hline \multicolumn{3}{|l|}{ Types of Marriage } \\
\hline Arrange & 277 & 52.6 \\
\hline Love & 250 & 47.4 \\
\hline \multicolumn{3}{|l|}{ Antenatal clinic visit } \\
\hline Yes & 430 & 81.6 \\
\hline No & 97 & 18.4 \\
\hline
\end{tabular}


Table 2. Risk of pregnancy co-morbidities among teenage pregnancy

\begin{tabular}{|lll|}
\hline Pregnancy co-morbidities & Yes & No \\
\hline Urinary tract Infection & $97(18.4 \%)$ & $430(81.6 \%)$ \\
\hline Threatened preterm & $68(12.9)$ & $459(87.1 \%)$ \\
\hline Premature rupture of membrane & $27(5.1 \%)$ & $500(94.9 \%)$ \\
\hline Antepartum Hemorrhage & $25(4.7 \%)$ & $502(95.3 \%)$ \\
\hline Intrauterine growth retardation & $11(2.1 \%)$ & $516(97.9 \%)$ \\
\hline Hyperemesis Graviderum & $10(1.9 \%)$ & $517(98.1 \%)$ \\
\hline Hypertension & $4(0.8 \%)$ & $523(99.2 \%)$ \\
\hline Sexual transmitted Infection & $2(0.4 \%)$ & $525(99.6 \%)$ \\
\hline
\end{tabular}

Among various complications related to pregnancy, the common complications found in this study were: urinary tract infection in 18.4\%; threatened preterm in $12.9 \%$; premature rupture of membrane in $5.1 \%$, and ante partum hemorrhage in $4.7 \%$. Other complications were: hyperemesis graviderum 1.9\%; intra uterine growth restriction 2.1\%; and, hypertension and STI $0.8 \%$ and $0.4 \%$ respectively. Gestational diabetes and polyhydraminous were found in each of two teenage mothers.

Table 3. Pregnancy outcome of teenage mother $(\mathrm{N}=527)$

\begin{tabular}{|c|c|c|}
\hline Pregnancy outcome & Number & $\%$ \\
\hline Abortion & 67 & 12.71 \\
\hline Ectopic pregnancy( laparotomy ) & 3 & 0.57 \\
\hline Vaginal Delivery & 317 & 60.15 \\
\hline Operative delivery & 76 & 14.42 \\
\hline Other Pregnancy complications & 64 & 12.14 \\
\hline \multicolumn{3}{|l|}{ With managed conservatively } \\
\hline \multicolumn{3}{|l|}{$\begin{array}{l}\text { Sub categorization of pregnancy } \\
\text { outcome }\end{array}$} \\
\hline \multicolumn{3}{|l|}{ Abortion $(n=67)$} \\
\hline Spontaneous & 51 & 76.1 \\
\hline Induced & 3 & 4.5 \\
\hline Missed & 3 & 4.5 \\
\hline Threatened & 10 & 14.9 \\
\hline \multicolumn{3}{|l|}{ Vaginal Delivery $(n=317)$} \\
\hline Spontaneous & 254 & 80.1 \\
\hline Induced & 57 & 18.0 \\
\hline Assisted & 6 & 1.9 \\
\hline \multicolumn{3}{|l|}{ Operative delivery $(n=76)$} \\
\hline Elective & 10 & 13.2 \\
\hline Emergency & 66 & 86.8 \\
\hline
\end{tabular}

Pregnancy outcome of mothers was broadly categorized in to abortion, ectopic pregnancy, operative delivery and vaginal deliveries, which revealed that, $12.76 \%$ of them had abortion with 3 induced due to gross congenital anomalies at mid trimester, 10 were threatened and manage conservatively and remaining were spontaneous abortion. Vaginal delivery accounts, $60.1 \%$ in which, six were vacuum assisted and $18.0 \%$ were induced and remaining were spontaneous delivery. Among the total delivery 76 of them had under gone operative delivery among which $86.8 \%$ had under gone emergency and only $13.2 \%$ were elective. Major causes of operative delivery were found to be cephalo pelvic disproportion (CPD) 30.3\%, fetal distress $21.1 \%$, primi breech 13.2 , non progress of labour $13.2 \%$ and prolonged labour 5.3\%.

Table 4. Neonatal outcome of teenage pregnancy ( $N=393)$

\begin{tabular}{|lll|}
\hline Neonatal outcome & Number & Percent \\
\hline Weight at birth & & \\
\hline$<2.5 \mathrm{~kg}$ & 109 & 27.7 \\
\hline $2.5 \mathrm{~kg}$ & 284 & 72.3 \\
\hline Preterm birth & 45 & 11.4 \\
\hline Congenital anomalies & 3 & 0.7 \\
\hline Neonatal death & 3 & 0.7 \\
\hline
\end{tabular}

Outcome of newborn shows that $72.3 \%$ babies born with weight $>2.5 \mathrm{~kg}$ and $27.7 \%$ of them were born to be weight $<2.5 \mathrm{~kg}$. Among them 11.4\% were preterm births, $0.7 \%$ found to have congenital anomalies of cleft palate and club foot and only three newborns died within 24 hours of birth due to birth asphyxia.

Table 5. Association between teenage pregnancy and demographic variables

\begin{tabular}{|c|c|c|c|}
\hline Variables & age $<17$ years & age $>17$ years & $P$ value \\
\hline \multicolumn{4}{|l|}{ Ethnicity } \\
\hline Brahmin/Chhetri & $26(21.1)$ & $141(34.9)$ & \\
\hline Newar & $12(9.8)$ & 46 (11.4) & \\
\hline Tamang & 44 (35.8) & $109(27.0)$ & 0.010 \\
\hline Dalit & $32(26.0)$ & $68(16.8)$ & \\
\hline Others & $9(7.3)$ & $40(9.9)$ & \\
\hline \multicolumn{4}{|c|}{ Educational Status } \\
\hline Illiterate & $10(8.1)$ & $6(1.5)$ & 0.0001 \\
\hline Literate & $113(91.9)$ & 398(98.5) & \\
\hline \multicolumn{4}{|l|}{ Economic Status } \\
\hline Low & $94(76.4)$ & $255(63.1)$ & \\
\hline Medium & $28(22.8)$ & $143(35.4)$ & 0.024 \\
\hline High & $1(0.8)$ & $6(1.5)$ & \\
\hline \multicolumn{4}{|l|}{ Types of marriage } \\
\hline Arrange & 45 (36.6) & $232(57.4)$ & \\
\hline Love & $78(63.4)$ & $172(42.6)$ & 0.0001 \\
\hline \multicolumn{4}{|c|}{ Antenatal clinic visit } \\
\hline Attended & $96(78.0)$ & $334(82.7)$ & \\
\hline Not attended & $27(22.0)$ & 70 (17.3) & 0.247 \\
\hline \multicolumn{4}{|l|}{ Newborn weight } \\
\hline$<2.5 \mathrm{Kg}$ & $29(33.3)$ & $80(26.1)$ & \\
\hline$>2.5 \mathrm{Kg}$ & $58(66.7)$ & $226(73.9)$ & 0.186 \\
\hline
\end{tabular}

Teenage pregnancy age less than 17 was found to be higher among tamang and dalit ethnic group and found statistically significant with $p=0.010$, low socio-economic status of women and age less than 17 is statistically 
significant with $p=0.024$. Similarly, age less than 17 and types of marriage and educational status of teenagers are highly significant with $p=<0.0001$ respectively. However, there are no statistically significant with age and address, occupation, ANC visit, pregnancy co-morbidities and weight of newborns.

\section{DISCUSSION}

Adolescent pregnancies are a global problem that occurs in high, middle, and low income countries. Around the world, adolescent pregnancies are more likely to occur in marginalized communities, commonly driven by poverty and lack of education and employment opportunities. ${ }^{4}$

The median age at first marriage among women in Nepal is 17.9 years, which is increased by 1 year overthe past decade. On average, women marry 4 yearsearlier than men (17.9 years versus 21.7 years). ${ }^{3}$ The mean age of teenagers at this study was $18.11 \pm 0.97849$. These findings indicate that women don't use contraceptive devices and get pregnant at early age. Similar findings were revealed at study conducted in India, mean ( \pm SD) age was $18.3 \pm 0.8$ years and slightly higher found in Bangladesh, $18.61 \pm 0.72$ and $18.5 \pm 0.7 .^{5-7}$ Age of less than 17 accounts $23.3 \%$ and more than 17 were $76.7 \%$. Similar findings were found in study conducted at Nigeria revealed $24.1 \%$ of teenager age between 14 to 16 years of age. ${ }^{8}$ However, only $2 \%$ of adolescent pregnancy with less than 17 years was found in study done at Kerala, India. ${ }^{9}$

Educational status, economic status and teenage pregnancy seem interrelated to each other as vicious cycle. In this study, less than 17 years of age groupwere found illiterate, with low economic background; and were associated with early marriage. Low socio-economic status and educational status were significantly associated with teenage pregnancy ( $p=0.024$ and $p=<0.0001$ respectively). This is supported by study conducted at northern part of India as low educational level and poor economic status were found significant in teenage pregnancy. Study also mentioned that, in a society with low literacy rate, people are more likely to follow the age social custom of marrying off a girl child at early age. ${ }^{10,11}$ Based on their subsequent lower education attainment, they may have fewer skills and opportunities for employment, often perpetuating cycles of poverty.Child marriage reduces future earnings of girls by an estimated $9 \%$. Nationally, this can also have an economic cost, with countries losing out on the annual income that young women would have earned over their lifetimes, if they had not had early pregnancies. ${ }^{2}$

All $(100 \%)$ teenage mothers were married in this study, this may be attributed to the culture of getting married at early age and moral value. This is also supported by Nepal demographic health survey, 2016, which revealed that median age at first marriage and first sexual intercourse is the same among women, 17.9 years. $^{3}$ Similar finding was found in studies conducted in Nepal and India, where culture and custom is very similar to area of this study. ${ }^{9,10,12}$ In contrary to this study, $72.3 \%$ of teenage pregnant were unmarried and un-booked. ${ }^{8}$ And $92.7 \%$ of teenage mothers were married. ${ }^{7}$

More than half of teenagers resides $58.6 \%$ at rural areas, similar findings was found in study conducted in Bangladesh showed 59.3\%. ${ }^{6}$ But study conducted in eastern part of Nepal showed that $65 \%$ of the teenagers are from urban residents. ${ }^{13}$ Nearly two-thirds of adolescents in Africa and Asia live inrural areas, but only one-fourth do in Latin America and the Caribbean. Whether adolescents live in rural or urban areas is a strong indicator of their levels of education and household wealth: Rural adolescents are poorer and, nearly everywhere, they are less educated than urban adolescents. ${ }^{14}$

Major complications like preeclmpsia, eclampcia, chronic hypertension, gestational hypertension were seen very less in this study group. Similar finding was observed at study conducted in Nepal and other countries. ${ }^{15-18}$ In contrary, many studies had showed that adolescent group are more prone to have pre-eclampsia and eclampsia compare to adult group. ${ }^{7,8,10,12,19}$

Common pregnancy co-morbidities revealed in this study were, Urinary tract infection $18.4 \%$, similar finding was observed in the study done by Santos et al. ${ }^{20}$ Lower urinary tract infection was high among younger teenagers and late teenagers, $26.95 \%$ and $24.35 \%$ respectively compare to adult, which was statistically significant with $p=0.01$ showed in study done in Romania. ${ }^{16}$ However, a study by Nili et al. showed only $2 \%$ of the teenage pregnancy had developed UTI during pregnancy. ${ }^{19}$

Vaginal delivery accounts $68.4 \%$ in this study, similar findings was observed in various studies, $71.7 \%, 66.2 \%$, $88.0 \%, 71.5 \%$ and $64.0 \%$. ${ }^{5,8,9,10,12}$ In contrary to this, $95.1 \%$ was found in compare to adult women, $77.2 \%$ study done in Nigeria and $21.3 \%$ in Bangladesh. ${ }^{7,6}$ Similarly, operative delivery in this study found to be less compare to other study, study conducted in Romania revealed that, teenage women are lower risk of caesarean and operative vaginal delivery in women $<20$ years of age compared with those between 20 and 24 years of age but Shah et al. found the rate of instrumental delivery significantly higher among the teenage group. ${ }^{17}$ However many other studies had higher rate of operative delivery than adult group..$^{5,8,10,12}$ In contrast, one study had even lower operative delivery than present study, $12 \%$ in study by Joseph and Eugene, only $4.9 \% .{ }^{7,9}$ Various literature has mentioned that teenage have immature pelvis and which causes cephalo pelvic disproportion (CPD) and might lead to high proportion of operative deliveries. However, present study had only $16.4 \%$ of operative delivery but among them, $30.3 \%$ of teenagers had under gone surgery due to CPD, which is strongly supported by study Joseph et al. and Medhi et al. ${ }^{9,10}$ However, study by Mukhopadhya, mentioned that 
teenagers give birth to either low birth weight or small for gestational age newborns. ${ }^{5}$ But, if we see at this study, the mean score of birth weight is $2.74 \pm 0.45898$. Similarly $72.3 \%$ of newborn born with weight more than $2.5 \mathrm{~kg}$ and $33.3 \%$ of newborns had weight less than $2.5 \mathrm{~kg}$. This finding was supported by study done in Teharan showed mean birthweight was $2731.4 \pm 679.5$ and LBW was $32.0 \%$, Medhi LBW 26.06, Nessa LBW 12.4\%, Eugene LBW 12.2\%, Joseph LBW 19.66\%.6,7,9,10,19 Teenage pregnancy age $<17$ was found to be higher among tamang and dalit ethnic group and found statistically significant with $p=0.010$. Study conducted by Sah showed similar findings as dalit and terai caste population are more likely to have teenage pregnancy, $p=<0.05 .^{13}$ This could be a reason that culture of getting married early, less educational level of parents and dowry system at terai belt of Nepal. If they get married to the aged man in early age, their parents has to pay little dowry. ${ }^{11}$

Low socio-economic status of women and age $<17$ is statistically significant with $p=0.024$. Similarly, age $<17$ and types of marriage and educational status of teenagers are highly significant with $p=<0.0001$ respectively. Love

\section{REFERENCES}

1. World Health Organization (WHO). Adolescent Pregnancy. fact Sheet, 2014.

2. World Health Organization (WHO). Guidelines on Preventing Early Pregnancy and Poor Reproductive Health, Outcomes among Adolescents in Developing Countries. WHO, Geneva. 2011.

3. Ministry of Health, Nepal; New ERA; and ICF. Nepal Demographic and Health Survey 2016. Kathmandu, Nepal: Ministry of Health, Nepal. 2017.

4. WHO, UNFPA; Girlhood, Not Motherhood: Preventing Adolescent Pregnancy. the United Nations Population Fund UNFPA, New York.

5. Mukhopadhyay P, Chaudhuri RN, Paul B. Hospital-based perinatal outcomes and complications in teenage pregnancy in India. $J$ Health Popul Nutr. 2010;28(5):495-500.

6. Nessa K, Zebunnesa M, Bari N, Saleh AB. Study of some sociodemographic factors in teenage pregnancy. Chattagram MaaO-Shishu Hospital Medical College Journal. 2014 Nov 29;13(3):21-5.

7. Eugen I, Jeremiah I, Atombosoba E. Teenage pregnancy and obstetric outcome: Acomparative study in urban Nigeria. NJOG. 2016; 21(1): 37-43.

8. Ayuba II, Gani O. Outcome of teenage pregnancy in the Niger Delta of Nigeria. Ethiopian journal of health sciences. 2012;22(1):45-50.

9. Joseph E, Thalamkandathil N. Maternal and perinatal outcome in adolescent. J. evid. Based Med. Health c. 2016;3(97):5344-7. DOI: 10.18410/jebmh/2016/1111

10. Medhi R, Das B, Das A, Ahmed M, Bawri S, Rai S. Adverse obstetrical and perinatal outcome in adolescent mothers associated with first birth: a hospital-based case-control study in a tertiary care hospital in North-East India. Adolescent health, medicine and therapeutics. 2016;7:37

11. Maharjan RK, Karki KB, Shakya TM, Aryal B. Child Marriage in Nepal: Research report. Plan Nepal, Save the Children, and World Vision International Nepal. 2012. ISBN 978-9937-2-5417-5 marriage is highly significant $(p=0.0001)$ with younger age group $<17$ years. This is supported by study done in Nepal revealed that, $32.1 \%$ get married by their willingness or love marriage due to influence of peers, it also illustrates that love marriage become a trends and also said that parents who has low economic status, they cannot organize marriage. So their children compelled to get married their own at early age. ${ }^{11}$

\section{CONCLUSION}

Maternal and fetal outcome and co morbidities among teenage pregnant women found less compare to other studies. Major pregnancy related morbidities such as hypertension, pre eclampsia and diabetes were found very less. Most common maternal morbidity found was urinary tract infection during pregnancy but statistically not significant. Similarly, newborn mean weight was more than $2.5 \mathrm{~kg}$ and new born death found very less. However, teenage pregnancy is significantly associated with low economic status, illiteracy status, willingness to marriage by teenagers and ethnicity.
12. Prasai S, KC N. Consequences of teenage pregnancy in Kathmandu valley. Journal of Institute of Medicine. April, 2017; 39:1.

13. Sah RB, Gaurav K, Baral DD, Jha N, Pokharel PK. Burden of Teenage pregnancies in hilly area of eastern region of Nepal. Journal of Nobel Medical College. 2014;3(1):13-9.

14. Darroch JE, Woog V, Bankole A, Ashford LS, Points K. Costs and benefits of meeting the contraceptive needs of adolescents. Guttmacher Institute. 2016 May. https://www.guttmacher.org/report/adding-itmeeting-contraceptive-needs-of-adolescents.

15. RC L, Baral R, Shrestha R, Gurung P, Lama S. Maternal and fetal outcomes of adolescent pregnancies at Patan hospital. NJOG. 2016 Jan-Jun; 21(1):11-3.

16. Socolov DG, lorga M, Carauleanu A, llea C, Blidaru I, Boiculese L, et al. Pregnancy during adolescence and associated risks: an 8-year hospital-based cohort study (2007-2014) in Romania, the country with the highest rate of teenage pregnancy in Europe. BioMed research international. 2017 Jan 1;2017.

17. Shah N, Rohra DK, Shuja S, Liaqat NF, Solangi NA, Kumar K, et al. Comparision of obstetric outcome among teenage and non-teenage mothers from three tertiary care hospitals of Sindh, Pakistan. JPMAJournal of the Pakistan Medical Association. 2011 Oct 1;61(10):963.

18. Egbe TO, Omeichu A, Halle-Ekane GE, Tchente CN, Egbe EN, Oury JF. Prevalence and outcome of teenage hospital births at the buea health district, South West Region, Cameroon. Reproductive health. 2015 Dec 1;12(1):118.

19. Nili F, Rahmati MR, Sharifi SM. Maternal and neonatal outcome in teenage pregnancy in Tehran Valiasr Hospital. Acta Medica Iranica. 2002;40(1):55-9.

20. Santos GH, Martins MD, Sousa MD, Batalha SD. Impacto da idade materna sobre os resultados perinatais e via de parto. Revista Brasileira de Ginecologia e Obstetrícia. 2009 Jul;31(7):326-34. 